\title{
APONTAMENTOS E REFLEXÕES SOBRE O SERTÃO DO BRASIL COLONIAL ${ }^{1}$
}

\section{NOTES AND REFLECTION ON BRAZIL'S BACKLANDS DURING THE COLONIAL PERIOD}

\author{
Nataniél Dal Moro²
}

\begin{abstract}
Resumo: Ao analisar aspectos do interior do Brasil Colonial os pesquisadores deparam-se e acabam, quase sempre, por problematizar fontes que, em determinadas momentos, retratam este território como sertão, local é que externado na historiografia contemporânea ora como conceito, categoria, chave explicativa, território físico, território geográfico, território geopolítico, paisagem, representação e/ou imaginário. Não raro há estudiosos que pensam e utilizam essa palavra como sinônimo de outro conceito, também bastante em evidência quando se faz um balanço historiográfico sobre o território que hoje compõe o Estado de Mato Grosso do Sul, localizado atualmente na Região Centro-Oeste do Brasil, qual seja, o conceito de fronteira, e esta inclusive com direito, também, às mais infinitas variações em sua compreensão: fala-se de fronteira física, fronteira geopolítica, fronteira agrícola, fronteira cultural, fronteira oeste, território fronteiriço ou então sertão fronteiriço. Tendo esta observação como central, este trabalho propõe-se a problematizar o conceito de sertão como uma palavra que comportou e comporta distintas realidades, e que politicamente continua a ser utilizada de variadas formas em nosso presente.
\end{abstract}

Palavras-chave: Brasil Colonial; Sertão; Fronteira.

Abstract: When analyzing aspects of the backlands of Colonial Brazil researchers found out and almost always end up problematizing sources that, in certain moments, portray this territory as the backland, a region that is expressed in contemporary historiography sometimes as a concept, category, explanatory key, physical territory, geographical territory, geopolitical territory, landscape, and/or imaginary representation. Often there are scholars who think and use that word as a synonym for another concept, also quite in evidence when we make an historiographical assessment over the territory that today comprises the states of Mato Grosso and Mato Grosso do Sul, located in the West- Central region of Brazil, whichever it is the concept of border, and this one with the right of, as well, to have endless understandings: there is talk about physical frontier, geopolitical frontier,

1 Este texto integra a primeira parte do meu relatório de pesquisa de Estágio Pós-Doutoral: MORO, Nataniél Dal. A política de ocupação de terras da Coroa Portuguesa entre os rios Paraguai e Paraná no século XVIII. Relatório de Pesquisa de Estágio Pós-Doutoral - Instituto de Investigação Científica e Tropical (IICT)/Centro de História de Além-Mar (CHAM), Universidade Nova de Lisboa (UNL), Lisboa, 2014.

2 Doutor em História Social pela Pontifícia Universidade Católica de São Paulo (PUC-SP) e Pós-doutorando pela Universidade Nova de Lisboa (UNL). CAPES Foundation, Ministry of Education of Brazil, Brasília/DF 70040 020, Brazil. Bolsista da CAPES Processo nº 18096/12-3. 
agricultural frontier, cultural frontier, West frontier, frontier territory or backlands frontier. Having this note as central, this work is proposed to discuss the concept of backlands as a word that has supported and supports different realities, and that politically continues to be used in various forms in our present.

Keywords: Colonial Brazil; Certain; Frontier.

\section{Introdução}

É muito difícil, talvez impossível mesmo, chegar-se a uma única conceituação do que é a história política do sertão (ou do atual oeste) do Brasil sem passarmos pelas definições que dele foram feitas no decorrer do tempo e por sujeitos dos mais variados, assim como dos propósitos de instituições e indivíduos em efetivar definições das mais diversas em relação a um território que está, em linhas gerais, no centro da América do Sul, e cujas cidades de Cuiabá e de Campo Grande, respectivamente capitais dos Estados de Mato Grosso e de Mato Grosso do Sul, aparecem, cada vez mais, como urbes de referência para aquilatar este conceito - qual seja: o sertão - que, dependendo das análises, limita-se a relatar o que constam em documentos do passado, transladando termos do outrora para explicar determinados intuitos que são materializados muito mais pelo presente do que descritos pelos documentos que nos chegam do passado. ${ }^{3}$

Tendo essa observação como central, propõe-se neste escrito problematizar o conceito de sertão como uma palavra que comportou e que ainda comporta distintas realidades.

\section{Formas de conceber o sertão}

O significado da palavra sertão, conforme o período e tendo em vista 0 sujeito que menciona o termo, apresenta e referencia diversas realidades. Não seria

3 Grosso modo, o sertão do século XVIII e também do XIX é o oeste do século XX e XXI. Neste trabalho o sertão (ou o oeste) estudado compreende mais especificamente o território do antigo sul do Estado de Mato Grosso, área que atualmente constitui o território físico do Estado de Mato Grosso do Sul, criado em outubro de 1977 por meio do desmembramento do então Estado de Mato Grosso. 
o caso de se fazer uma enumeração pormenorizada do estado da arte destas muitas definições que se atribuíram para esta palavra que, por vezes, é retratada na historiografia contemporânea ora como conceito, categoria, chave explicativa, território físico, território geográfico, território geopolítico, paisagem, representação e/ou imaginário, isso para externar somente algumas das formas de como o sertão foi concebido. Não raro há pesquisadores que pensam e utilizam essa palavra como sinônimo de outro conceito, também bastante em evidência quando se faz um balanço historiográfico sobre o território que hoje compõe os Estados de Mato Grosso e de Mato Grosso do Sul, qual seja, o conceito de fronteira, e esta inclusive com direito, também, às mais infinitas variações em sua compreensão: fala-se de fronteira física, fronteira geopolítica, fronteira agrícola, fronteira cultural, fronteira oeste, território fronteiriço ou também sertão fronteiriço. ${ }^{4}$

O intuito de elencar estas mesmas formas de conceituar um mesmo objeto de estudo é, sobretudo, a de enfatizar que o sertão e a fronteira não possuem definições estanques. Nesse sentido, vê-se que, e isso é salutar, uma mesma documentação dá origem para diversas formas de se pensar um mesmo passado no presente, e a História não deixa de ser isso mesmo: a análise do presente sobre o outrora ou, sejamos mais enfáticos, a atuação política (sempre do presente) sobre como o passado deve ser, ou é, pensado no presente.

Feita essa observação, o objetivo deste escrito é o de pensar o que há no presente daquilo que foi produzido no passado e que nos chega por meio de algumas fontes. Externar essa questão parece-me essencial para discutir, muito mais do que conceituar pontualmente, a palavra sertão (oeste ou fronteira) no campo da historiografia. Este trabalho, por sua vez, remete-nos para uma tarefa que

$4 \quad$ O conceito de fronteira, e suas variantes, foi largamente utilizado em estudos acadêmicos no Brasil, em especial pela Antropologia, pela Geografia e pela Sociologia desde a década de 1940, e também em períodos mais recentes. Dentre os autores que se valeram deste conceito e popularizaram no meio científico a expressão, destacam-se sobretudo Darcy Ribeiro, Octavio lanni e José de Souza Martins. A esse respeito, ver IANNI, Octavio. A luta pela terra: história social da terra e da luta pela terra numa área da Amazônia. Petrópolis: Vozes, 1978 e MARTINS, José de Souza. Fronteira: a degradação do outro nos confins do humano. São Paulo: Companhia das Letras, 1997. Nesse sentido, importante ressaltar que Martins afirma serem inadequadas as apropriações do conceito de fronteira nos moldes do pensamento elaborado por F. Turner e que por vezes são usadas para pensar a fronteira brasileira, pois o caso norte-americano é um e o brasileiro é outro. Cf. MARTINS, José de Souza. O tempo da fronteira: retorno à controvérsia sobre o tempo histórico da frente de expansão e da frente pioneira. Tempo Social: revista de Sociologia da USP, São Paulo, v. 8 , n. 1, p. 25-70, maio 1996. 
se ramifica em dois pontos: $1^{\circ}$ ) um que pergunta sobre os projetos dos sujeitos que produziram o que hoje chamamos de fontes e $2^{\circ}$ ) um que indaga a respeito da relação destas fontes com outras realidades, em suma, com os projetos de outros sujeitos, sejam estes vitoriosos ou não. E faremos esta reflexão por meio das duas problemáticas antes postas e que estão, assim preferimos pensar, em constante diálogo.

Visando evitar possíveis transladações do mapa do Brasil atual para o mapa (ou mapas seria o mais adequado) existente no início do século XVIII, façamos algumas ponderações de grande utilidade didática ao nosso trabalho. O expressivo número de mapas, esboços, anotações, e mesmo meros croquis ou simples cópias de outras cópias, algumas delas com informações ainda não compreendidas a respeito do Brasil Colonial (do que hoje se entende por Brasil Colonial) deixa margem para a produção, neste agora, de um Brasil que ia do leste para o oeste e possuía vários milhões de hectares e, por vezes, e isso dependendo da fonte consultada, da produção de um mapa do Brasil Colonial que não se afastava muitos quilômetros do litoral, ficando restrito às áreas que concentravam atividades extrativas, como a do pau-brasil ou das chamadas drogas do sertão. ${ }^{5}$

Por vezes, outras documentações sinalizavam que o conhecimento dos domínios do sertão era feito muito mais pelos rios do que por terra e que não havia fixação efetiva pelos locais que os colonizadores passavam, e isso para nos determos apenas em fontes produzidas por instituições lusitanas ou a elas ligadas, e teoricamente subordinadas, como é o caso de considerável parcela dos manuscritos existentes na Biblioteca Nacional de Portugal. ${ }^{6}$ Quando analisamos materiais produzidos em língua espanhola, ou de outras nações, pode-se, igualmente, chegar

$5 \quad$ Referimo-nos mais especificamente aos conteúdos das seguintes obras: TAUNAY, Affonso d'Escragnolle. Collectanea de mappas de cartographia paulista antiga. São Paulo: Melhoramentos, 1922 e ADONIAS, Isa. Imagens da formação territorial brasileira. Rio de Janeiro: Fundação Emílio Odebrecht, 1993.

6 A respeito desta questão, consultar em especial os manuscritos intitulados: Biblioteca Nacional de Portugal (BNP). Relatório sobre o interior de Mato Grosso [manuscrito]. 25 f. [17--]. In: Miscelânea - Coleção de 9 peças, por A. Lourenço Caminha, e CÁCERES, Luiz de Albuquerque de Mello Pereira e. Diário de uma viagem feita do Rio de Janeiro até Vila Bela, capital de Mato Grosso, em 1775. [manuscrito]. 13 f. 1775. In: MONIZ, José António. Inventario Secção XIII - Manuscriptos Collecção Pombalina. Lisboa: Biblioteca Nacional, 1889. 
a outros entendimentos. ${ }^{7}$ No conjunto, vemos que as fontes existentes defendem, cada qual, a existência de realidades que não raro entram em conflito umas com as outras, porém, isso não quer dizer que estes posicionamentos divergentes, por causa do referido, anulem-se. Ao contrário, essas divergências devem ser entendidas como indícios muito válidos à produção do conhecimento histórico neste nosso presente a respeito daquele passado. ${ }^{8} \mathrm{E}$ é neste momento que podemos pensar o espaço físico, ou o território compreendido por ele, como sendo uma área de sertão ou de fronteira.

No século XVIII o sertão compreendia, em linhas gerais, o espaço físico não ocupado e nem portador de modos de vida que se aproximassem ou fossem próximos dos europeus, daí uma das definições de que o sertão (a palavra em si) derivaria de deserto, desertão, ou, simplesmente, sertão, que quase sempre aparece grafado de duas formas em manuscritos já seculares: certáo ou certóes. ${ }^{9}$ No Diccionario prosodico de Portugal e Brazil, por sua vez, consta que sertão é o "mato longe da costa." ${ }^{10}$ Sertão aparece também como sinônimo de bosque, mata, mato, savana. No documento de um Anônimo, intitulado Carta de um passageiro de monção, que data de 1785 , consta que no sertão "o mais tudo é bosque intrincadíssimo e medonho."11

E quem vive no sertão, por vezes chamado de "sertão oculto e habitado de

$7 \quad$ É o caso de algumas das obras deste autor: AZARA, Felix de. Descripcion y historia de la antigua provincia del Paraguay del rio de La Plata. Madrid: Imprenta de Sanchiz, 1847 e AZARA, Felix de. Demarcación de limites entre el Paraguay y el Brasil. Madrid: Imprenta de Sanchiz, 1847.

$8 \quad O$ passado como tal é muito mais uma metáfora do que propriamente uma realidade, uma vez que o passado é sempre condicionado pela tarefa de se pensar o ocorrido no outrora por meio de problemáticas colocadas no presente. Logo, construir o passado é um trabalho do presente, dos sujeitos que vivem o agora, e não do passado enquanto tal. O passado, por ele mesmo, não se faz e não se insinua para o presente. Parece-me oportuno destacar aqui que o passado (a análise que se faz dele e a edificação de histórias), comporta também significativa carga de ucronias ou invenções históricas, tal qual já mencionaram alguns historiadores, como é o caso de Braudel e de Hobsbawm. Ver BRAUDEL, Fernand. Reflexões sobre a história. São Paulo: Martins Fontes, 1992, p. 334 e HOBSBAWM, Eric. Sobre história: ensaios. São Paulo: Companhia das Letras, 1998, p. 17.

$9 \quad$ Esta grafia derivaria do latim desertus, no sentido de ser um local que estivesse no centro de um território ou de uma região. Consultar, a esse respeito, o escrito de BARROSO, Gustavo. A origem da palavra 'sertão'. Boletim geográfico, Rio de Janeiro, IBGE, v. 52, p. 401-403, jun. 1947. A ideia de que o sertão constituía-se de "desertos indecisos" é mencionada também em documentos do século XVIII, tal como se pode observar no seguinte material: Arquivo Histórico Ultramarino (AHU). PARECER do Conselho Ultramarino enviado por Rodrigo César de Meneses. Lisboa Oriental, 8 jan. 1732. Mato Grosso-AHU. Doc. 80.

10 CARVALHO, António José de. Diccionario prosodico de Portugal e Brazil. 4. ed. rev. e muito augment. Porto: Lopes \& Cia., 1890, p. 824. O nome completo do autor é António José de Carvalho e João de Deus. 
muito Gentio chamado Caoam e Cavaleiro"12, foi denominado de "sertanejo(a)", sendo este um sujeito cuja característica principal era o de ser "rústico." E ao que tudo indica esta definição, já na segunda metade do século XIX, permanecia quase que inalterada. Neste caso o sertão "sem moradores", nas palavras de Escragnolle Taunay, foi chamado de "sertão bruto" e correspondia aos "campos de Miranda e Pequiry ou da Vaccaria e Nioac, no Baixo Paraguay."13

Também são comuns as reflexões que mostram o sertão como um local distante da Corte portuguesa, do litoral, dos "maiores núcleos populacionais", enfim, do movimento, das atividades comerciais e da civilização. ${ }^{14}$ Mostra-se o sertão, tanto em documentos já seculares como em produções acadêmicas do presente, como um local grande, imenso, vasto, desconhecido, despovoado de homens brancos e/ou pouco habitado, portador de uma natureza bruta e misteriosa, e que em geral deveria ser dominada a todo o custo. ${ }^{15}$

Não raro o mesmo local é visto como incivilizado, inóspito, ínvio, insalubre, intransitável, selvagem, perigoso, malsão, reduto de moléstias das mais variadas

11 ANÔNIMO. Carta de um passageiro de monção. In: TAUNAY, Afonso d'Escragnolle. Relatos monçoeiros. Coletânea, introdução e notas de Afonso de E. Taunay. São Paulo: Livraria Martins, 1953, p. 203-214, em específico p. 206.

12 JUZARTE, Theotônio Jose. Diário da navegação do rio Tietê, rio Grande, rio Paraná e rio Guatemi em que se dá relação de todas as coisas mais notáveis destes Rios, seu curso, sua distância, e de todos os mais Rios, que se encontram, Ilhas, perigos, e de tudo o acontecido neste Diário, pelo tempo de dois anos, e dois meses. Que principia em 10 de março de 1769. In: TAUNAY, Afonso d'Escragnolle. Relatos monçoeiros. Coletânea, introdução e notas de Afonso de E. Taunay. São Paulo: Livraria Martins, 1953, p. 215-273, em específico p. 217. O manuscrito original que Taunay consultou pertence ao Museu Paulista, tal como o próprio Autor informou.

13 DINARTE, Sylvio (TAUNAY, Escragnolle). Céos e terras do Brasil. Scenas e typos, quadros da natureza, fantasias. Rio de Janeiro: Typ. De G. Leuzinger \& Filhos, 1882, p. 10.

14 As seguintes palavras, quais sejam: "maiores núcleos populacionais", constam entre aspas pelo fato de que só podemos pensar a existência de núcleos populacionais mais ou menos povoados dentro de determinadas formas de compreender a realidade social. Sendo assim, a filosofia que ampara esta concepção volta-se muito mais para os núcleos criados por não-índios. $\mathrm{E} o$ passo que considera esses núcleos como relevantes, desconsidera, por sua vez, a existência de outras formas populacionais que, se pensadas por meio de outra concepção, podem nos fazer entender que no sertão também havia significativos "núcleos populacionais", porém não nos mesmos moldes da sociedade européia.

15 Voltando-se para a literatura que está mais ligada aos estudos geográficos, o sertão aparece, na maioria das vezes, como um local distante da costa. Contudo, também constam relatos dos mais diversos sobre a palavra sertão, e que não se restringem apenas ao Brasil, mas abarcam áreas da Europa e da África. O termo é pensado como local em que havia mato, como terra sem comunicação e como local desconhecido ou ainda não povoado. ANTONIO FILHO, Fadel David. Sobre a palavra "sertão": origens, significados e usos no Brasil (do ponto de vista da Ciência Geográfica). Ciência geográfica, Bauru, v. XV, n. 1, p. 84-87, jan./dez. 2011. 
que podiam, com muita frequência e rapidez, matar as pessoas. ${ }^{16}$ Alguns sujeitos que estiveram no sertão, como foi o caso do Sargento-Mor Theotônio José Juzarte, mostram este local como permeado por rios "caudalosos e perigosos". Este Sargento também descreve o sertão como abrigo de "perigos consideráveis", destacando que muitos dos que por ele passam ficam enfermos, sentem fome, sofrem com a chuva, trovoadas e os insetos, tal como no caso de uma "nuvem de marimbondos de dentro do mato, que mordendo a toda gente causou lástima". ${ }^{17}$ As pessoas, não raro, também adoecem, ficam enfermas e morrem. ${ }^{18}$

O sertão foi pensado também como habitat de pessoas afastadas das leis e instituições, em particular as notadamente designadas como políticas ou religiosas. O sertão foi visto, por vezes, como um local que "não era controlado ou habitado por portugueses, mas por bárbaros; era ainda caótico, não cristão, não civilizado e hostil a valores e princípios como justiça, cristandade, estabilidade, boa administração." ${ }^{19}$

Retratou-se também o sertão como um local impróprio para que pessoas civilizadas ali residissem, já que nele havia parcos alimentos e a água era salobra, logo, não seria possível fincar raízes neste ambiente, cuja geografia, em muitos locais, era praticamente desconhecida. Por vezes o sertão funcionou como uma punição à conduta de determinados homens, sendo então pensado o sertão como uma prisão ao "ar livre", um local de regeneração dos hábitos, tal como nos indica uma carta de 5 de fevereiro de 1780. Nela, Manuel Gonçalves de Miranda encaminhou petição de Domingos Lourenço ao secretário de estado da Marinha e Ultramar Martinho de Melo e Castro solicitando que o seu filho, de 24 anos, fosse transportado para a Capitania de Mato Grosso como forma de "castigo pela sua vida libertina e licenciosa." ${ }^{20}$

16 JUZARTE, Theotônio José. Diário da navegação do rio Tietê, rio Grande, rio Paraná e rio Guatemi em que se dá relação de todas as coisas mais notáveis destes Rios, seu curso, sua distância, e de todos os mais Rios, que se encontram, Ilhas, perigos, e de tudo o acontecido neste Diário, pelo tempo de dois anos, e dois meses. Que principia em 10 de março de 1769. In: TAUNAY, op. cit., 1953, p. 215-273.

17 JUZARTE, Theotônio José. Diário... In: TAUNAY, op. cit., 1953, p. 238 e 257.

18 JUZARTE, Theotônio José. Diário... In: TAUNAY, op. cit., 1953, p. 217 e 225-228.

19 DOMINGUES, Ângela. Monarcas, ministros e cientistas. Mecanismos de poder, governação e informação no Brasil colonial. Lisboa: Universidade Nova de Lisboa/Universidade dos Açores/Centro de História de Além-Mar, 2012, p. 49.

20 Arquivo Histórico Ultramarino (AHU). CARTA de Manuel Gonçalves de Miranda a Martinho de Melo e Castro. Anexo: 4 doc. AHU-MATO GROSSO, cx. 19, doc. 44. AHU-CU-010, Cx. 21, D. 1270. 
Em outros casos, no entanto, o sertão significava "a fonte inesgotável de abastecimento de mão-de-obra praticamente gratuita, utilizada por todos os extractos da sociedade colonial luso-brasileira. E, nesse sentido, o sertão podia também ser para os moradores dos núcleos urbanos sedeados ao longo dos rios um local de oportunidade e lucro."21

Nesse sentido, parte dos documentos analisados enfatiza que dois grandes grupos habitavam o local chamado sertão: um era o dos homens que viviam no sertão (e ele era bem diverso) e, o outro, o dos indígenas (pensados como povos autóctones) que lá já estavam, fossem eles caracterizados como mansos ou bárbaros. Os primeiros, segundo alguns relatos do século XVIII, eram aqueles que tinham sido agrupados em missões, catequizados e aceitavam as doutrinas transmitidas pelos religiosos, embora nem sempre em sua totalidade; já os outros, às vezes também chamados de gentios bárbaros, foram retratados como bravos, indóceis, infiéis, já que não se deixam inculcar pelos ensinamentos proferidos pelos cristãos. $^{22}$ Não raro os gentios bárbaros também foram descritos como agressores de religiosos, homens brancos e, inclusive, indígenas pertencentes a outras tribos, chegando mesmo a matá-los. ${ }^{23}$ Ademais, no caso dos guaicurus, que eram detestados pelo "grande soldado" Ricardo Franco de Almeida Serra, falou-se que eles eram petulantes, soberbos, dissimulados, cruéis e "se julgavam uma nação de heróis e fidalgos."24

Feitas essas observações, que espero terem mostrado que o que se entende como sertão é ao mesmo tempo uma categoria do passado e uma categoria do presente, pois é constantemente referenciada na sociedade pelo pensar acadêmico no decorrer da segunda metade do século $X X$ assim como o foi em 21 DOMINGUES, op. cit., 2012, p. 49.

22 Os indígenas receberam várias denominações daqueles que, no decorrer de séculos, os retrataram, seja por terem estudado as suas ações ou com eles convivido/entrado em confronto mais diretamente. Por vezes foram pensados genericamente apenas como "índio". Em outros casos como "gentio" (ou "pagão") que passou a representar o oposto de cristão. Foram denominados também como "inimigos" ou "contrários", "negros da terra" ou "negros brasis", "índios mansos" (aqueles controlados) e "índios bravos" (aqueles que eram hostis ou bárbaros). BRASIL: 500 ANOS. Disponível em: <http://brasil500anos.ibge.gov.br/territorio-brasileiro-e-povoamento/historiaindigena/nomes-e-classificacao-dos-indios>. Acesso em: 10 jan. 2014.

23 LOPES, Joaquim Francisco. As derrotas de Joaquim Francisco Lopes. Campo Grande: IHGMS, 2007.

24 MELO, Raul Silveira de. Um homem do dever: Cel. Ricardo Franco de Almeida Serra. Rio de Janeiro: Biblioteca do Exército, 1964, p. 96 e LOPES, op. cit., 2007, p. 100. 
documentos já seculares, entendo que é preciso, agora, problematizar os motivos que levaram o homem dito "branco ou civilizado" do século XVIII a querer conhecer ou estar no sertão, numa área de fronteira entre os domínios portugueses e espanhóis na região central da América do Sul. Parece-me quase lugar-comum então pensar o sertão como um local de fim de mundo e associá-lo com a possibilidade de se encontrar, neste lugar, coisas que pudessem ter algum valor, como indígenas de podiam ser escravizados e terras com metais preciosos.

Alguns autores, cujos estudos são tomados há décadas como clássicos, e não apenas por significativa parcela dos pesquisadores universitários, mostram-nos que o sertão tornou-se interessante aos olhos dos colonizadores no decorrer de vários períodos devido às atividades antes mencionadas, em especial a preação de índios e a procura de metais preciosos, no entanto, destaca-se reduzidamente a questão de que este local, dependendo da análise que se faz, pode mostrar outras realidades. ${ }^{25}$ Como bem externou Eric Hobsbawm, "as perguntas e as respostas" não "surgem naturalmente do estudo do material. Em geral, não existe material algum até que nossas perguntas o tenham revelado." 26

Nesse sentido, pouco ou quase nenhum destaque é dado para as análises que enfatizam ser o sertão um local que é o centro e não a periferia de uma determinada civilização ou modo de vida, que foi, ou que ainda continua sendo, densamente povoado por indígenas ${ }^{27}$, que é uma região portadora de flora e fauna bastante diversificas e, sobretudo, possuidor de uma cultura ao menos tão civilizada quanto àquela existente nas demais regiões do mundo, tal como se pode observar quando se alteram as problemáticas lançadas sobre os documentos produzidos há

$25 \quad$ Um destes autores, provavelmente o mais conhecido de todos, especialmente entre os estudiosos universitários brasileiros e portugueses, é Sérgio Buarque de Holanda. E essa análise se faz perceptível, em particular, nas seguintes obras: HOLANDA, Sérgio Buarque de. Monções. Rio de Janeiro: Casa do Estudante do Brasil, 1945; HOLANDA, Sérgio Buarque de. Caminhos e fronteiras. Rio de Janeiro: José Olympio, 1957 e HOLANDA, Sérgio Buarque de. O Extremo Oeste. São Paulo: Brasiliense/Secretaria de Estado da Cultura, 1986.

26 HOBSBAWM, Eric. Sobre história: ensaios. São Paulo: Companhia das Letras, 1998, p. 220.

$27 \quad O$ termo povos indígenas pode aqui ser perfeitamente alterado para o termo povos autóctones. Em outras palavras, pessoas que vivem em determinada terra desde tempos imemoriais, isso no caso de populações nativas da América. Ou também pessoas que estão há mais tempo do que outras em determinado lugar, não necessariamente apenas na América mas em qualquer outra parte do mundo. Nesse sentido, os indígenas (termo muito usual no Brasil) são povos autóctones em relação aos europeus, que chegaram em "terras" ocupadas há mais tempo pelos nativos. 
séculos. $^{28}$

Poderíamos então, diante do exposto, perguntar-nos não sobre as afirmações contidas nos documentos, mas sim sobre os silêncios presentes nas fontes, bem ao estilo da análise a contrapelo de Walter Benjamin ${ }^{29}$, e que, como tal, produzem sentidos tão expressivos quanto quaisquer outras documentações, tanto quanto quaisquer "outras verdades", tanto quanto quaisquer outros relatos e análises que nos chegam a respeito do passado e que só se fazem presente devido à existência de interesses, notadamente os políticos. ${ }^{30}$ Teríamos de nos indagar por quais motivos os documentos mostram o sertão como um lugar deserto, mas que devia ser ocupado "com povoadores"31, afastado dos "centros de civilização" (se é

$28 \quad$ Esta análise, que podemos caracterizar como pouco problematizadora, é muito comum em livros didáticos (e também, falemos claramente, em artigos científicos) que, ao tentarem produzir uma história com base em fontes primárias, limitam-se ao trabalho de citar excertos das fontes e acabam, ao desenvolver esta tarefa, por se descuidar do trabalho de interpretação do conteúdo destas fontes e da historicidade que as mesmas possuem e nas quais foram produzidas. A produção veiculada particularmente por autores memorialistas, e em revistas editadas pelos Institutos Históricos e Geográficos no Brasil, também acaba por priorizar este tipo de produção. No caso de artigos ditos científicos, em muitos casos, essa realidade também é extremamente perceptível. Há artigos que, ao analisarem "um ou dois documentos" que contém a palavra sertão, acabam por generalizar a todo o restante do sertão as afirmações contidas nestes "um ou dois documentos". Outro problema que me parece relevante é o de que muitas das fontes documentais que datam do século XVIII, e que são utilizadas por pesquisadores para a produção de artigos científicos, calcamse em transcrições feitas e publicadas em revistas originárias notadamente de Institutos Históricos e Geográficos, contudo, confrontando o conteúdo das transcrições e o conteúdo dos originais, por vezes, há partes que foram suprimidas. Logo, reside aqui uma expressiva problemática que diz respeito ao conteúdo e a interpretação deste, e assim sendo, as possíveis análises provenientes destas fontes que possuem como fontes aquelas que são primárias. Ver em especial PRADO, Francisco Rodrigues do. História dos índios cavalleiros, ou da nação Guaycurú, escrita no real presídio de Coimbra por Francisco Rodrigues do Prado - Transladada de um manuscrito oferecido ao Instituto pelo sócio correspondente José Manoel do Rosário. Revista do Instituto Histórico e Geographico do Brazil, Rio de Janeiro, Imprensa Nacional, 1908 (originalmente publicado em 1839), 3. ed., tomo I, n. 1, p. 21-44 e PRADO, Francisco Rodrigues do. História dos Índios Cavaleiros ou da Nação Guaicuru. Campo Grande: IHGMS, 2006. Observar também o escrito de LOPES, op. cit., 2007.

29 Segundo Walter Benjamin, os bens culturais são, ao mesmo tempo, tanto um indicativo de civilização como de barbárie de uma sociedade, uma vez que, "em termos de bens culturais, tudo, sem exceção, tem uma origem que [...] não pode" ser rememorada "sem horror. [...] Não há documento de cultura que não seja ao mesmo tempo um documento da barbárie. E assim como os próprios bens culturais não estão livres de barbárie, também não o está o processo de transmissão com que eles passam de uns a outros." BENJAMIN, Walter. Teses sobre filosofia da história. In: KOTHE, Flávio (Org.). Sociologia. São Paulo: Ática, 1985, p. 157.

30 O sentido da palavra político não se limita, aqui, ao entendimento dado ao termo político em especial pelos pensadores do século XIX, notadamente pelos positivistas, mas abarca outras realidades, e nestas inclui-se, sobretudo, a social. A presente reflexão pode ser encontrada na obra de SODRÉ, Nelson Werneck. Formação histórica do Brasil. 2. ed. São Paulo: Brasiliense, 1963, p. IX. Para este pensador, todo escrito "deriva de uma posição política" do autor e, como tal, é politicamente partidário de uma forma de pensar o mundo.

31 JUZARTE, Theotônio José. Diário da navegação... In: TAUNAY, op. cit., 1953, p. 217. 
que estes de fato existem tal qual parcelas do pensamento externam), perigoso, malsão e infestado por animais ${ }^{32}$ e pestes?

Por quais motivos os indígenas são retratados como bárbaros, hostis, traiçoeiros e assassinos, e outros povos, na maior parte das vezes, como sendo o oposto destas qualificações ${ }^{33}$

De acordo com uma parte dos documentos produzidos no século XVIII, o sertão era efetivamente um local tal qual determinadas fontes externaram que ele o era? Numa análise que prime pela narrativa, no sentido desta ser uma transladação, quase que uma cópia, ou até mesmo, sejamos mais enfáticos, um plágio escancarado de afirmações contidas inicialmente nas fontes, e que o escritor/pesquisador passa a incorporá-las ao seu texto, pode-se afirmar que sim. E isso somente porque essa narrativa linear vê na documentação a própria História, o próprio passado em sua essência e, mais do que isso, a verdade, e, por isso mesmo, pode assegurar que o sertão era o que, de fato, o texto gráfico, ou qualquer outro documento, afirma que ele era.

Portanto, via esta forma de análise, não há o que questionar sobre as afirmações (e, mais ainda, sobre as práticas dos sujeitos) que passaram a descrever, qualificar e rotular o sertão. Elas constituem o passado e estes documentos do passado devem ser lidos como aqueles que nos possibilitam escrever a história no presente. O positivismo fez, aliás faz, e considera esta forma de escrever a história como válida e digna de mérito ainda hoje. Contudo, utilizando-

$32 \quad$ No Diário de Theotônio José Juzarte consta que os rios do sertão representavam "perigos consideráveis" de "bichos, caças e os trabalhos que se expõem os que por eles navegam." Sobre as serpentes, afirmou ele que "são estas cobras tão venenosas, que mordendo em qualquer pessoa instantaneamente fica sem vista, e entra a exalar sangue pelos olhos, boca, e nariz, e pelas unhas, e o mais que dura vivo são vinte, e quatro horas [...]." In: TAUNAY, op. cit., 1953, p. 217 e 225.

33 A qualificação dos indígenas como portadores de tais características, largamente demeritivas, foi e continua sendo muito forte na literatura que informa aos mais diversos presentes e sujeitos sobre qual é a "essência" destes povos. Em contrapartida, a mesma literatura, e que por vezes é reeditada pelos Institutos Históricos e Geográficos no Brasil, acaba por enaltecer grandemente a figura do colonizador, do bandeirante, do desbravador de sertões, do pioneiro, do pecuarista e, mais recentemente, também do fazendeiro e do agricultor que, cada qual ao seu modo, mas sempre de um modo elogioso, levam ou continuam levando "progresso" e "civilização" para o sertão ou o oeste do Brasil. MORO, Nataniél Dal. Os pioneiros e a edificação de uma cidade moderna. In: O pensar da elite sobre o povo comum: espaço público, viver urbano e reterritorialização do centro da cidade de Campo Grande (décadas de 1960-70). 2012. 310 f. Tese (Doutorado em História Social) - Programa de Estudos Pós-Graduados em História, Pontifícia Universidade Católica de São Paulo (PUC-SP), São Paulo, 2012, Cap. 1, p. 28-68. 
se de outra análise, o sertão pouco se aproxima do que a narrativa linear afirma que ele é e que ainda hoje continua-se a pensar que ele assim sempre o foi. Se invertermos a pergunta, na verdade a problemática, podemos dizer que o Ocidente, na análise dos indígenas, é que era um local tal qual os europeus intitulavam o sertão. Na verdade não, o que estes documentos nos falam sobre o sertão é muito mais devido ao fato do europeu não conhecer o local chamado sertão do que propriamente pelo fato do local ser tudo isso que há séculos se diz que ele foi. Ou em essência a falta do que julgavam que ele devia ser, uma vez que é nos projetos advindos sobremaneira com o lluminismo que estes valores foram consolidados na sociedade da Europa Ocidental.

Diante do desconhecido, penava-se, sofria-se, passava-se fome e também sede, e até morria-se, algo que não era raro entre os não-indígenas que se embrenhavam pelo sertão. ${ }^{34}$ A situação aqui é semelhante, e podemos assim aproximar por meio de um comparativo, à de um idioma que não conhecemos: as pessoas podem falar, e comunicarem-se entre si, mas se nós não tivermos conhecimento do que elas falam, do que dizem, da língua que utilizam, não entenderemos o que os signos (e os seus significados) externados representam para determinada cultura. Contudo, isso não quer dizer que pelo fato de nós não entendermos o que elas dizem, que o que elas falam é sem sentido para elas e para o universo no qual elas passaram a existir socialmente. Quando muito, o é só para

$34 \quad$ Os dados de que se têm acesso entre indígenas e não-indígenas que morriam no sertão são dispersos. Contudo, já se tornou largamente conhecida aquela informação que afirma que os primeiros morriam em menor número percentual do que os segundos, isso quando o motivo da morte era o fato de saber se destrinchar no sertão e contornar as adversidades que porventura surgissem por se estar naquele ambiente. Alguns autores mostram que a morte de não-índios, ocorrida pelos mais variados motivos no sertão, foi retratada como um sinal de bravura dos que se embrenhavam por terras pouco ou nada exploradas pelo homem branco, dando a estes a conotação de heróis por terem empreendido os trabalhos que realizaram, notadamente o de desbravar o sertão. Ver em especial as duas obras: TAUNAY, Afonso d'Escragnolle. Relatos sertanistas. Coletânea, introdução e notas de Afonso de E. Taunay. São Paulo: Livraria Martins, 1953 e, sobretudo, Id. Relatos monçoeiros. Coletânea, introdução e notas de Afonso de E. Taunay. São Paulo: Livraria Martins, 1953. Nelas pode-se observar também como os não-índios, como os sertanistas, são alçados ao patamar de sujeitos merecedores de honrarias e lembranças por aumentar os domínios da Coroa portuguesa sobre o sertão já que desbravaram os sertões, muitos deles pagando com a vida para efetivar esta empreitada. Por vezes encontramos também em obras produzidas pela historiografia mais recente, ao fazerem uma análise dessas obras citadas, a afirmação de Taunay, qual seja, a de que "São impressionantes as dificuldades enfrentadas por aqueles que se aventuravam a chegar às minas do Cuiabá." Ver COSTA, Maria de Fátima. História de um país inexistente: o Pantanal entre os séculos XVI e XVIII. São Paulo: Estação Liberdade/Kosmos, 1999, p. 183. 
nós, mas não para elas.

O sertão, então, aparece assim para muitos dos europeus, ou seja, como um local portador de uma natureza não conhecida e por isso mesmo perigosa. Poderíamos afirmar mesmo que este é o caso da maioria daqueles que estiveram neste território: eles estão no sertão, andam pelo sertão, e, principalmente, navegam pelo sertão em determinados períodos do ano, mas não conseguem se destrinchar tanto quanto os sujeitos que são nativos do local chamado sertão.

No entanto, quem conhecia o sertão não pensava de forma alguma sobre este local nos mesmos termos que muitos dos europeus que passaram/viveram neste local. Para inúmeros povos autóctones, os populares indígenas, o sertão era um território bastante propício aos projetos de sociedade que eles tinham há séculos e nos quais alicerçaram suas culturas e saberes. A flora e a fauna davam conta de saciar, e inclusive de satisfazer plenamente, as necessidades das populações ali existentes, e que em alguns casos era bem superior àquela de algumas das maiores cidades européias. ${ }^{35}$ As práticas culturais dos indígenas, em particular as vestimentas utilizadas e as crenças professadas, também não eram em nada desairosas aos olhos dos que nelas nasceram e foram criados.

Ao veicularmos essa forma de análise, não se trata aqui também, em absoluto, de desmerecer os documentos existentes e as suas verdades e as políticas que os produziram, notadamente aqueles legados pelas autoridades lusitanas e/ou brasileiras sobre o território hoje chamado por grande parcela dos estudiosos como Brasil Colonial, Brasil Colônia ou Colônia portuguesa na América. Cabe, muito mais, considerar que "a história deve cada vez mais dar lugar ao desafio da relatividade das culturas e dos sistemas de valores: relatividade da época estudada", logo, não há apenas um sertão e nem mesmo o sertão tão somente, mas sim várias culturas que pensaram e pensam o que muitos chamam de sertão, e estes vários suportes documentais nos permitem, por seu turno, pensar e mostrar

$35 \quad$ Alguns relatos mostram que, na América no período do "descobrimento", havia determinados locais que possuíam uma concentração populacional equivalente, e até superior, daquela que existia em muitas das cidades européias mais densamente povoadas. Sobre isso ver os seguintes escritos: RIBEIRO, Darcy. Culturas e línguas indígenas do Brasil. Educação e Ciências Sociais. Rio de Janeiro, v. 1, n. 6, 1957; INSTITUTO BRASILEIRO DE GEOGRAFIA E ESTATÍSTICA. Brasil: 500 anos de povoamento. Rio de Janeiro: IBGE, 2000 e BACCI, Massimo Livi. Breve história da população mundial. Lisboa: Edições 70, 2013, p. 64-75. 
diversos sertões e os sujeitos que nele estiveram, viveram e empreenderam distintos projetos, alguns materializados e outros que ficaram apenas no plano das ideias. ${ }^{36}$ Devido a isso, entendemos que o sertão não foi e não é apenas um, mas sim que o território pensado como sertão comportou e comporta vários sertões, no sentido de várias verdades constituírem o que, resumidamente, se pode chamar por constitutivo desta realidade e dos sujeitos que nela estavam ou estão.

Entretanto, também não se trata aqui de deixar de externar que é essencial veicular a análise de que o sertão, tal como muitos de nós hoje o conhecemos é, sobretudo, um sertão que foi dado a conhecer pelos sujeitos que não eram ou que não viviam no sertão e que, ao veicularem as adjetivações e os valores que intentaram propagar a respeito deste território, tinham outros interesses além dos de simplesmente dar a conhecer para quem não fosse do sertão o que havia, de fato, neste território, não raro pensado como uno. ${ }^{36}$ Por este prisma, o sertão de que falaram os que neste lugar chegaram é um sertão que foi forjado particularmente pelo olhar de colonizadores europeus sobre culturas e ambientes com os quais pouca familiaridade tinham e que, em geral, queriam, segundo alguns, alterá-lo e, segundo muitos outros, até fazer por completo desaparecer as culturas ali existentes já que tinham como intuito fazer prevalecer os seus modos de vida sobre os modos de vida existentes naquele sertão. ${ }^{37}$

36 O autor não se refere, evidentemente, ao sertão em seu escrito, mas sim à Idade Média. No original consta: "não havia apenas uma Idade Média: Bizâncio não era o Ocidente latino, e o Islão fazia concorrência ao cristianismo -, e relatividade, ainda mais, das nossas próprias maneiras de refletir e de falar." SCHMITT, Jean-Claude. Ano mil - ano 2000, qual a atualidade da Idade Média? In: LE GOFF, Jacques et al. Viva o Ano 1000! A modernidade da Idade Média. Lisboa: Teorema, 2000, p. 47.

36 A historiografia existente, pelo menos no aspecto da economia, mostra-nos que há vários sertões e que eles são mais visíveis do que outras realidades. Por meio do que o sertão ofereceu ao campo econômico é possível ver, hoje, que o sertão não era apenas um, mas sim que havia muitos sertões. O que há é, por outro turno, antes, uma predominância textual da produção historiográfica que analisa o sertão e enfatiza-o como uno, mostrando-o como um local sem nuances. Isso, no entanto, deve-se sobremaneira ao fato de se transladar valores contidos nos relatos consultados, sem que se faça a devida mediação entre o que foi relatado e as implicações políticas de o fazê-lo, logo, o relato não deve ser pensado como sendo a realidade existente no sertão, mas sim como uma posição política de determinados sujeitos do outrora que relataram o que o sertão lhes parecia ser e cujos relatos também estavam comprometidos com valores específicos de determinadas sociedades que se mostravam como civilizadoras frente a culturas ditas incivilizadas ou bárbaras.

37 Nem todas as ações dos colonizadores europeus, que aqui podemos pensar como autoridades em geral, primaram por "fazer por completo desaparecer as culturas" indígenas, entretanto, há que se mencionar com destaque neste nosso presente (muito mais do que no passado em que elas foram produzidas) que a literatura originada no outrora sempre deu maior ênfase para os modos de viver dos colonizadores. Neste sentido, essa política contribuiu 


\section{Referências}

\section{Bibliografia}

ANTONIO FILHO, Fadel David. Sobre a palavra "sertão": origens, significados e usos no Brasil (do ponto de vista da Ciência Geográfica). Ciência geográfica, Bauru, v. XV, n. 1, p. 84-87, jan./dez. 2011.

BACCl, Massimo Livi. Breve história da população mundial. Lisboa: Edições 70, 2013.

BARROSO, Gustavo. A origem da palavra 'sertão'. Boletim geográfico, Rio de Janeiro, IBGE, v. 52, p. 401-403, jun. 1947.

BENJAMIN, Walter. Teses sobre filosofia da história. In: KOTHE, Flávio (Org.). Sociologia. São Paulo: Ática, 1985.

BRASIL: 500 ANOS. Disponível em: <http://brasil500anos.ibge.gov.br/territoriobrasileiro-e-povoamento/historia-indigena/nomes-e-classificacao-dos-indios>.

Acesso em: 10 jan. 2014.

BRAUDEL, Fernand. Reflexões sobre a história. São Paulo: Martins Fontes, 1992.

DOMINGUES, Ângela. Monarcas, ministros e cientistas. Mecanismos de poder, governação e informação no Brasil colonial. Lisboa: Universidade Nova de Lisboa/Universidade dos Açores/Centro de História de Além-Mar, 2012.

MARTINS, José de Souza. Fronteira: a degradação do outro nos confins do humano. São Paulo: Companhia das Letras, 1997.

. O tempo da fronteira: retorno à controvérsia sobre o tempo histórico da frente de expansão e da frente pioneira. Tempo Social: revista de Sociologia da USP, São Paulo, v. 8, n. 1, p. 25-70, maio 1996.

MORO, Nataniél Dal. Os pioneiros e a edificação de uma cidade moderna. In: O pensar da elite sobre o povo comum: espaço público, viver urbano e reterritorialização do centro da cidade de Campo Grande (décadas de 1960-70). 2012. 310 f. Tese (Doutorado em História Social) - Programa de Estudos PósGraduados em História, Pontifícia Universidade Católica de São Paulo (PUC-SP), São Paulo, 2012.

RIBEIRO, Darcy. Culturas e línguas indígenas do Brasil. Educação e Ciências Sociais. Rio de Janeiro, v. 1, n. 6, 1957.

SCHMITT, Jean-Claude. Ano mil - ano 2000, qual a atualidade da Idade Média? In: LE GOFF, Jacques et al. Viva o Ano 1000! A modernidade da Idade Média. Lisboa: Teorema, 2000.

SODRÉ, Nelson Werneck. Formação histórica do Brasil. 2. ed. São Paulo: Brasiliense, 1963.

\section{Fontes}

decisivamente para "fazer por completo desaparecer as culturas" indígenas, embora na prática isso não tenha ocorrido. 
ADONIAS, Isa. Imagens da formação territorial brasileira. Rio de Janeiro: Fundação Emílio Odebrecht, 1993.

ANÔNIMO. Carta de um passageiro de monção. In: TAUNAY, Afonso d'Escragnolle. Relatos monçoeiros. Coletânea, introdução e notas de Afonso de E. Taunay. São Paulo: Livraria Martins, 1953, p. 203-214.

Arquivo Histórico Ultramarino (AHU). CARTA de Manuel Gonçalves de Miranda a Martinho de Melo e Castro. Anexo: 4 doc. AHU-MATO GROSSO, cx. 19, doc. 44. AHU-CU-010, Cx. 21, D. 1270.

PARECER do Conselho Ultramarino enviado por Rodrigo César de Meneses. Lisboa Oriental, 8 jan. 1732. Mato Grosso-AHU. Doc. 80.

AZARA, Felix de. Demarcación de limites entre el Paraguay y el Brasil. Madrid: Imprenta de Sanchiz, 1847.

Descripcion y historia de la antigua provincia del Paraguay del rio de La Plata. Madrid: Imprenta de Sanchiz, 1847.

Biblioteca Nacional de Portugal (BNP). Relatório sobre o interior de Mato Grosso [manuscrito]. 25 f. [17--]. In: Miscelânea - Coleção de 9 peças, por A. Lourenço Caminha.

CÁCERES, Luiz de Albuquerque de Mello Pereira e. Diário de uma viagem feita do Rio de Janeiro até Vila Bela, capital de Mato Grosso, em 1775. [manuscrito]. 13 f. 1775. In: MONIZ, José António. Inventario Secção XIII - Manuscriptos Collecção Pombalina. Lisboa: Biblioteca Nacional, 1889.

CARVALHO, António José de. Diccionario prosodico de Portugal e Brazil. 4. ed. Porto: Lopes \& Cia., 1890.

COSTA, Maria de Fátima. História de um país inexistente: o Pantanal entre os séculos XVI e XVIII. São Paulo: Estação Liberdade/Kosmos, 1999.

DINARTE, Sylvio (TAUNAY, Escragnolle). Céos e terras do Brasil. Scenas e typos, quadros da natureza, fantasias. Rio de Janeiro: Typ. de G. Leuzinger \& Filhos, 1882.

HOLANDA, Sérgio Buarque de. Caminhos e fronteiras. Rio de Janeiro: José Olympio, 1957. . Monções. Rio de Janeiro: Casa do Estudante do Brasil, 1945.

1986. . O Extremo Oeste. São Paulo: Brasiliense/Secretaria de Estado da Cultura,

JUZARTE, Theotônio Jose. Diário da navegação do rio Tietê, rio Grande, rio Paraná e rio Guatemi em que se dá relação de todas as coisas mais notáveis destes Rios, seu curso, sua distância, e de todos os mais Rios, que se encontram, Ilhas, perigos, e de tudo o acontecido neste Diário, pelo tempo de dois anos, e dois meses. Que principia em 10 de março de 1769. In: TAUNAY, op. cit., 1953, p. 215-273.

LOPES, Joaquim Francisco. As derrotas de Joaquim Francisco Lopes. Campo Grande: IHGMS, 2007.

MELO, Raul Silveira de. Um homem do dever: Cel. Ricardo Franco de Almeida Serra. Rio de Janeiro: Biblioteca do Exército, 1964.

PRADO, Francisco Rodrigues do. História dos índios cavalleiros, ou da nação Guaycurú, escrita no real presídio de Coimbra por Francisco Rodrigues do Prado Transladada de um manuscrito oferecido ao Instituto pelo sócio correspondente José Manoel do Rosário. Revista do Instituto Histórico e Geographico do Brazil, Rio de Janeiro, Imprensa Nacional, 3. ed., tomo I, n. 1, p. 21-44, 1908 (originalmente 
publicado em 1839).

História dos Índios Cavaleiros ou da Nação Guaicuru. Campo Grande: IHGMS, 2006.

TAUNAY, Affonso d'Escragnolle. Collectanea de mappas de cartographia paulista antiga. São Paulo: Melhoramentos, 1922.

. Relatos monçoeiros. Coletânea, introdução e notas de Afonso de E. Taunay. São Paulo: Livraria Martins, 1953.

. Relatos sertanistas. Coletânea, introdução e notas de Afonso de E. Taunay. São Paulo: Livraria Martins, 1953. 